\title{
Allocation of Assets on the Ghana Stock Exchange (GSE)
}

\author{
Lord Mensah $^{1}$, R. K. Avuglah ${ }^{1} \&$ Vincent Dedu ${ }^{1}$ \\ ${ }^{1}$ Department of Mathematics, Statistics and Actuarial Science, College of Science, Kwame Nkrumah University of \\ Science and Technology, Ghana \\ Correspondence: Lord Mensah, Department of Mathematics, Statistics and Actuarial Science, College of Science, \\ Kwame Nkrumah University of Science and Technology, Ghana. Tel: 233-20-267-1916. E-mail: \\ lmensah.cos@knust.edu.gh
}

Received: December 8, 2012

Accepted: December 31, 2012

Online Published: April 8, 2013

doi:10.5430/ijfr.v4n2p108

URL: http://dx.doi.org/10.5430/ijfr.v4n2p108

\begin{abstract}
In this paper, we use stock price data between the years 2007 and 2010 to investigate the allocation of assets on the GSE. The Classical Markowitz optimization method shows that, the most profitable portfolio is obtained by investing $90 \%$ of wealth in non-financial assets and $10 \%$ in financial assets. Risk aversive investor who goes for the minimum risk portfolio has to invest $80 \%$ in non-financial assets and $20 \%$ in financial assets. We also find that, if the investor decides to split his wealth among the financial and non-financial asset equally, his profit will not be as much as the minimum and the optimum risk portfolio. In effect, there is a reward for risk on the GSE but the Markowitz optimization strategy never exceeds the buy and hold strategy of the market index.
\end{abstract}

Keywords: portfolio allocation, asset returns, buy and hold strategy, tangency portfolio (TP), minimum variance portfolio (MVP)

\section{Introduction}

Markowitz (1952) portfolio theory provides the basis for modern theory of portfolio choices. The intuition behind his theory is maximizing the expected returns while minimizing the risk of a portfolio. From his concepts, the utility of the investor is mainly a function of the first two moments (mean and variance) of returns. In this paper, we use mean (expected returns) and risk (standard deviation) interchangeably. The theory also incorporates diversification effects, investor preferences and expectations of return and risk of all assets considered. Detail of the mean-variance theory indicates that investors prefer portfolios of securities with high-expected returns in relation to risk. The application of the theory demands knowledge of the expected returns (mean) of all assets under consideration and their standard deviations (risk). Pairwise correlation of all assets is also considered. With the information on mean, standard deviation and correlation, a set of efficient portfolios can be computed. These portfolios maximize expected returns for various levels of risk. They represent the best-invested alternatives given the selected assets. An investor who can tolerate more risk might choose a portfolio on the higher point of the frontier, while the risk-averse investor would be more likely to choose a portfolio at the lowest point on the frontier.

Most of the early studies support the theory. In summary, Fama and French (2004) stated that, although the Markowitz mean-variance model has empirical setbacks, it is nevertheless the most widely used model in both academic and real-world applications. However, some studies argue that the classical implementation of the theory ignores the effect of measurement error on the inputs. For instance, Jorion (1992) proposes a resampling approach to minimize estimation error. Specifically, he asserts that, considering sample variability, there is no evidence that the optimal portfolio outperformed the world index in the period 1978 to 1988.

The Markowitz model requires that the relevant distribution of the asset returns be normal. However, some empirical evidence suggests that many financial returns are not normally distributed. Evidence of studying single asset at a time show that, a typical asset returns have heavier tails than implied by the normal assumption and are often not symmetric (see. Kon (1984), Mills (1995), Markowitz and Usmen (1996) and Peiro (1999). Because of the fat tail in the distribution of returns, several researchers have suggested the adoption of the third and the fourth moments in the Markowitz optimization model. For instance, Hung and Yang (2010) propose a generalized Markowitz portfolio investment model, which takes into consideration measures of skewness and kurtosis into the classical Markowitz 
investment model. With these third and fourth moments in the objective function, they found that the shape of the efficient frontier differ from that of the classical model of Markowitz.

The Markowitz theory has been tested extensively on various developed markets, but there is still less much study in relation with the theory on frontier markets like the Ghana Stock Exchange (GSE). This paper has a number of goals which includes filling in the gap in the existing literature on the frontier markets (GSE specifically). Firstly, the key objective of the paper is to investigate the allocation of wealth among financial and non-financial assets on the GSE. The paper also seeks to test whether the classical Markowitz method of portfolio optimization yields more profit on the GSE than the buy and hold strategy. We find that an investor who is more risk aversive (minimum variance) should invest $80 \%$ of his wealth on non-financial assets and $20 \%$ on the financial assets. On the other hand, the less risk aversive investor should allocate about $90 \%$ of his wealth to non-financials and $10 \%$ on to the financial. The result of the empirical analysis also rejects the null hypothesis of the Markowitz optimization strategy being more profitable than the buy and hold strategy. In effect, the findings seem to be against the applicability of the Markowitz optimization model on the GSE between the periods of our study. Portfolio managers will be better off in engaging in passive trading strategies by holding the market portfolio than to focus on active trading strategies by allocating assets.

The rest of the paper is organized as follows: The next section discusses the data and the descriptive statistics of the returns series. In section III, we investigate the pair wise correlation of all the assets under consideration. Section IV, considers the Markowitz optimization techniques for allocating wealth among financial and the non-financial assets. The last section concludes the study.

\section{Data and the Descriptive Statistics of Returns}

Monthly price, market capital (price time's shares outstanding) and dividend data on the 39 listed firms between the periods January 2007 to December 2010 are taken from the GSE electronic library. We consider the three-month Treasury bill rate as the short-term risk-free rate (taken from the Ecobank research group) in the same period of the stock data. The all-share composite index from the GSE is considered as the market index (value-weighted). We group the stocks on the GSE into financial and non-financials. The stocks in the recent GSE financial index are used as our criteria for grouping stocks into financials. The rest of the stocks are classified as non-financial. The financial group consists of 12 stocks and the non-financial group consists of 27 stocks. We compute dividend adjusted returns for each adjacent month by using the formula

$$
R_{i t}=\frac{P_{i t}-P_{i t-1}+D_{i t}}{P_{i t-1}}
$$

where $R_{i t}$ is the month $t$ return of the stock of the firm $i$. The $P_{i t}$ and $D_{i t}$ represents the price and the dividend paid by the firm $i$ at the month $t$. Each month, we group stocks in both financial and non-financial groups to form portfolios. Due to the illiquidity nature of some stocks on the GSE, we value-weight the stocks in each portfolio based on their market capital. That is, each month portfolio return is computed as

$$
R_{p t}=\sum_{i=1}^{N} w_{i t-1} R_{i t}
$$

where $R_{p t}$ represents the portfolio returns. The $w_{i t}$ is the weight contributed by each stock and it is computed as the $M C_{i t-1} / \sum_{i=1}^{N} M C_{i t-1}$, where $M C_{i t}$ is the market capital of the security of the firm $i$ at month $t$. In all cases, $N$ represents the number of stocks in each portfolio. We compute the value-weighted portfolio in order to capture the size (liquidity) contribution of each asset in the portfolio. We did not consider equal-weight portfolios because small stocks dominate in equal weighting, whereas the large market capital stocks stand out with value weighting. The market value-weighted portfolio will also reflect the best return evolution of the investable assets on the GSE. 
Table 1 below shows the descriptive statistics of the All Share index, the non-financial portfolio, the financial portfolio and the short-term (three-month) Treasury bill rate.

Table 1. Descriptive statistics of GSE returns (Jan. 2007 - Dec. 2010)

\begin{tabular}{lllll}
\hline & All & Non-Fin & Fin & T-bill \\
\hline Mean & $0.04^{* *}$ & $0.05^{* *}$ & 0.03 & $0.01^{* *}$ \\
t-stats & $(4.19)$ & $(4.49)$ & $(1.68)$ & $(19.47)$ \\
Std & 0.07 & 0.08 & 0.12 & 0.00 \\
S-Ratio & 0.62 & 0.66 & 0.25 & 2.87 \\
\hline
\end{tabular}

Note: This table reports the means, standard deviation (Std) and the sharpe ratio (S-Ratio) of the returns series of the All share index (All), the financial (Fin), the non-financial (Non-Fin) and the 91 days T-bills. We also show the t-statistics for the test of hypothesis that the mean is significantly different from zero (in parenthesis). **: Significance at $5 \%$ level.

Evidence from this table indicates that, over the period of our study, the all share index and the non-financial portfolio on the GSE yield statistically significance returns. Specifically, the all share index produces a profit of about four basis points (with t-statistics of 4.19) whereas the non-financial index has a profit of five basis points (with t-statistics of 4.49). The financial stock does not seem to produce statistically significance returns (economically significance returns of three basis points with t-statistics of 1.68). The 91-day Treasury bill shows lower returns but highly significant. This might be attributed to the lower volatility recorded on T-bills in our period of the study. The significance in profit of the non-financial stocks reflects in the Sharpe ratio of its portfolio.

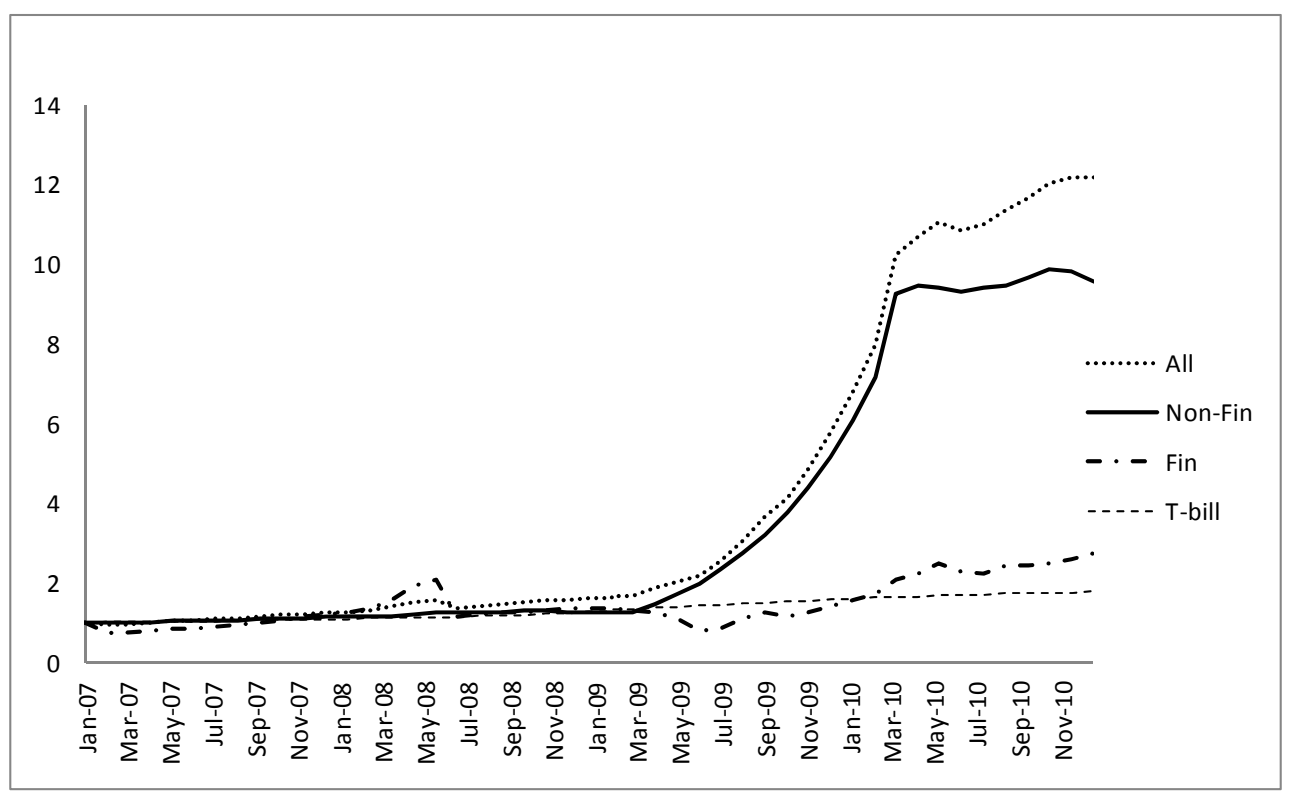

Note: The graph depicts the of evolution one Ghana cedi invested all the asset from January 2007 to December 2010.

Figure 1. Evolution of GHC 1 invested

Figure 1 illustrates the growth of the return on GHC 1 invested in the individual portfolios we considered in the period of our study. If $R_{p t}$ denote the return of the portfolio at the end of the period $t$, the return evolution is constructed as follows:

$$
R_{p t}=R_{p t-1}\left(1+\sum_{i=1}^{N} w_{i t-1} R_{i t}\right)
$$


It is clear from Figure 1 that, there is no much difference in the return growth of all the assets under consideration in the first half of the period. On the other hand, the second half period shows a dramatic rise in the All-share index and the non-financial index. The financial asset shows some increase but very slow. Relative to the risky assets, the T-bill does perform slowly in the period of our study. Specifically, GHC 1 invested in the T-bills at the beginning of the period will not yield up to GHC 2 at the end of the period. There seem to be reward for risk as the risky assets (All share index, Financial and Non-Financial) yield higher returns than the risk-free rate proxy (T-bills).

\subsection{Asset Pair-wise Correlations}

Because the classical Markowitz model considers the pair-wise correlation between the assets, we compute the correlation between the all-share index, the financial portfolio, the non-financial portfolio and the 91-day Treasury bill (shown in Table 2). We test for the hypothesis whether the correlations are significantly different from zero. The p-values of the hypothesis tests are in parenthesis.

Table 2. Correlation matrix (Jan. 2007 - Dec. 2010)

\begin{tabular}{lllll}
\hline & All & Non-Fin & Fin & T-bill \\
\hline All & 1 & & & \\
Non-Fin & 0.89 & 1 & & \\
& $(0.00)$ & & & \\
Fin & 0.58 & 0.15 & 1 & 1 \\
T-bill & $(0.00)$ & $(0.31)$ & & \\
& 0.38 & 0.50 & -0.08 & $(0.57)$ \\
\hline
\end{tabular}

Note: This table shows the correlation matrix of the returns from the All-share index, Non-Financials, Financials and the 91 days Treasury Bill rate on the GSE.

It is not surprising to see a strong correlation between the all-share index and the other assets considered. That is the correlation between the All-share index and the financial portfolio is $58 \%$ with p-value of approximately zero. On the other hand, the non-financial portfolio records a correlation of $89 \%$ (p-value of approximately zero) with the all-share index. This is not amazing as the constituent stocks in the two portfolios are sub-sets of the All-share index. Surprisingly, there is a strong correlation between the short-term T-bill and the All-share index ( $38 \%$ correlation with a p-value of 1\%). This shows that there is a positive comovement of the All-share index and the short-term 91-days Treasury bill. As indicated in the third and the fourth column of Table 2, the correlation between financial on one hand and non-financial and Treasury bill on the other hand is not significant. The 91-days Treasury bill has a strong correlation with the non-financial portfolios. Based on the correlation between the assets and the benefit of diversification (indicated in the assumptions behind the Markowitz model), we study the allocation of wealth among the financial and non-financial assets on the GSE in the next section.

\section{Asset Allocations}

As stated earlier, the principle of Markowitz portfolio theory places emphasis on the benefit of portfolio diversification. This is the optimum way to combine portfolio of different asset classes. The portfolio construction depends on the market risk and the return of each asset class and on the correlation between different asset classes. For diversification purpose, we consider the allocation of wealth among the financial and the non-financial portfolios. We discard the all-share index and the 91-day Treasury bill because of the strong significant pair-wise correlation they have with the financial and the non-financial portfolios (from the p-values in Table 2).

For the allocation of wealth among the financial and the non-financial portfolios, we employ the optimization technique. This technique is a process that regulates the most trade-off between contesting interests. In the portfolio management setting competing interest is risk reduction and return improvement. Asset allocation is another form of optimization. The objective of the optimization is to identify portfolio weights that produce the lowest level of risk for various levels of expected returns.

We wish to identify the combination of financial and non-financial portfolios on the GSE that produce the lowest level of risk (standard deviation) for varying amount of expected return. As indicated earlier the objective is to minimize risk. The first constraint is that the weight of each asset is greater than zero. We also face a second 
constraint by allocating the entire wealth to some combinations of financial and non-financial portfolios. The third constraint ensures that the weighted average expected returns of the financial and the non-financial portfolio is the average of the optimized portfolio. We will not leave any part of the portfolios that is not invested. This implies that, the weight we allocate to financial and the non-financial portfolio must sum up to one. As stated earlier the pre-requisite to the use of Markowitz optimization theory is the relevant distribution of asset returns be normally distributed and the utility is only a function of the first two moments. In order to ensure that our data satisfy this requirement, we tested for the normality of the return distributions by using the Jarque and Bera (1987) test. We find out that, the portfolio returns are normally distributed and the classical Markowitz theory is applicable to our data.

We solve the classical Markowitz optimization problem below for the minimum variance (risk) portfolio (MVP):

$$
\text { Minimize } \sigma_{p}=\sigma_{f}^{2} w_{f}^{2}+\sigma_{n o n}^{2} w_{\text {non }}^{2}+2 w_{f} w_{\text {non }} \operatorname{cov}\left(r_{f}, r_{\text {non }}\right)
$$

subject to:

$$
\begin{aligned}
& r_{f} w_{f}+r_{n o n} w_{\text {non }} \geq r_{p} \\
& w_{f} \geq 0 \\
& w_{\text {non }} \geq 0 \\
& w_{f}+w_{\text {non }}=1
\end{aligned}
$$

where $r_{*}, w_{*}, \sigma_{*}$ are respectively the returns, weight of each asset in the portfolio and the standard deviation of the returns of financial(f) and the non-financial(non) portfolios. For the tangency portfolio (TP, optimum portfolio), we maximize the Sharpe ratio (SR, reward to variability) subjected to similar constraints as the MVP optimization problem.

Table 3. Allocation of assets on the GSE

\begin{tabular}{lllllllll}
\hline & EQW & MVP. & & \multicolumn{7}{l}{ TP } \\
\hline Expected return & 0.0287 & 0.0352 & 0.0354 & 0.0356 & 0.0360 & 0.0375 & 0.0376 & 0.0380 \\
Standard deviation & 0.0763 & 0.0619 & 0.0619 & 0.0620 & 0.0622 & 0.0639 & 0.0641 & 0.0648 \\
SR & 0.3754 & 0.5684 & 0.5717 & 0.5745 & 0.5792 & 0.5870 & 0.5869 & 0.5862 \\
Non-Fin & 0.5000 & 0.7990 & 0.8086 & $0 . .8178$ & 0.8361 & 0.9056 & 0.9093 & 0.9276 \\
Financials & 0.5000 & 0.2010 & 0.1914 & 0.1822 & 0.1639 & 0.0944 & 0.0907 & 0.0724 \\
\hline
\end{tabular}

Note: In this table, we use the Markowitz optimization technique to find the possible weight an investor on the GSE will assign to the financial and non-financial portfolio to obtain the minimum variance portfolio (MVP) and the tangency portfolio (TP). It also presents the possible expected returns for splitting wealth equally among the two portfolios (EQW). The sample period is January 2007 to December 2010.

In all cases, we do not allow a short sale as the practice is rare in emerging markets like the GSE. Table 3 shows the possible solutions of the optimization problem. It is clear from the table that, if an investor decides to group his wealth equally between the financial portfolio and the non-financial portfolio, his reward to variability (SR) is 0.38 .

On the other hand, if the investor decides to go for the minimum variance portfolio (MVP) his reward to variability is 0.57 , and it is higher than the equally weighted portfolio (EQW). It is observed that, the standard deviation (risk) is higher for equally weighted portfolio than the minimum variance portfolio. The minimum variance portfolio suggests the investor allocate about $80 \%$ of his capital to the non-financial portfolio and $20 \%$ to the financial portfolio. The table also shows that, from the MVP to the tangency portfolio (portfolio with the highest return to variability), the percentage allocates to financial asset decreases and that of non-financial asset increases. This is coupled with an increase in the Sharpe ratio (SR). Risk averse investor will invest in the minimum variance portfolio. An investor ready to take up some risk has to invest in the tangency portfolio (high reward to variability ratio). 


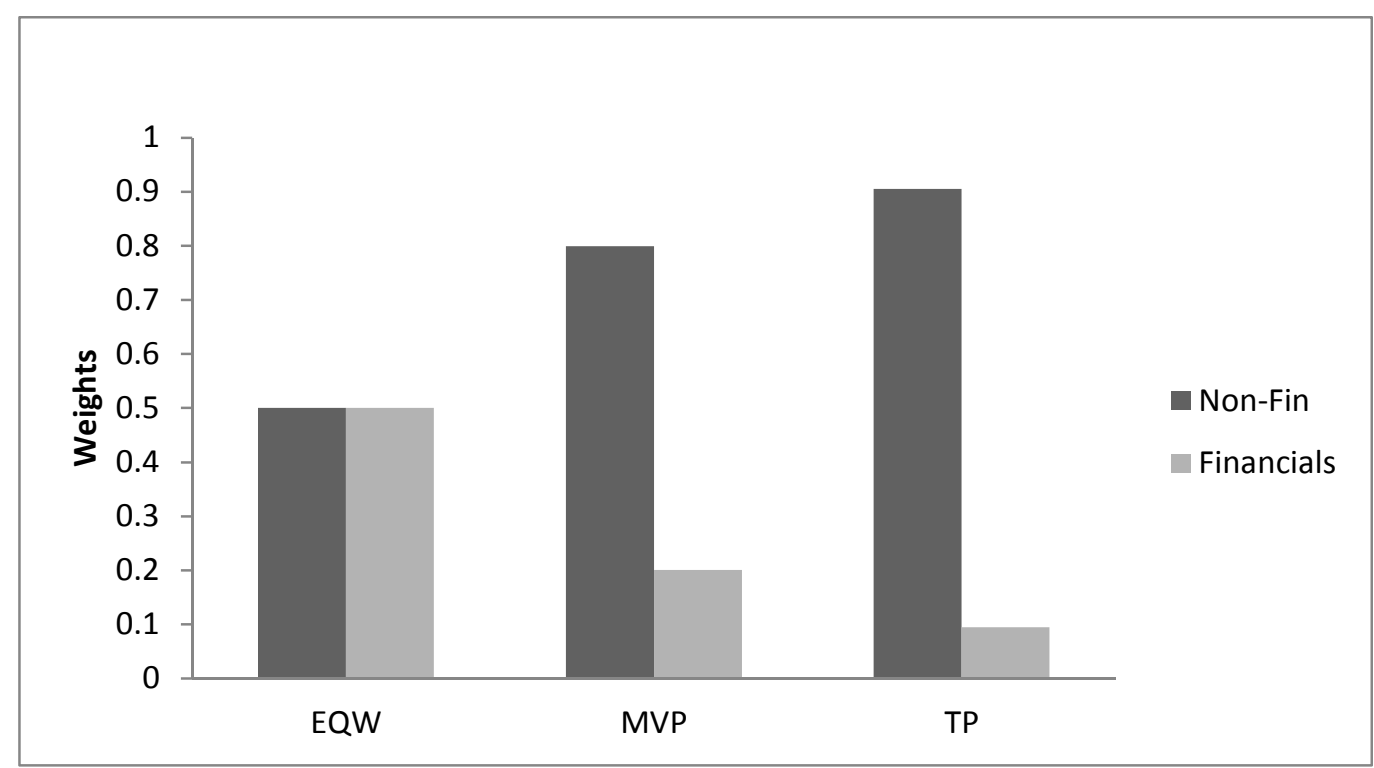

Figure 2. The proportion of optimal overall portfolios

This means, the investor will allocate about $10 \%$ of his capital in the financials and $90 \%$ in non-financials. The proportions of the optimal overall portfolios are summarized in Figure 2 below.

The optimal portfolios, when mapped on the risk-return plane form a curve known as the efficient frontier. Each investor based on his individual utility function finds the appropriate point on this curve, which then prescribes an optimum allocation between the different portfolios such as the financial and the non-financial portfolio. Figure 3 below depicts the possible set of optimal portfolios on the GSE. It shows the optimal risky portfolio as the TP and the minimum risky portfolio as the MVP. It is imperative to know that the returns of the efficient set portfolios are less than the returns of the market portfolio (all share index returns). This indicates that on the GSE, allocating portfolios using the Markowitz optimization will not yield a higher portfolio return than the buy and hold strategy on the market portfolio.

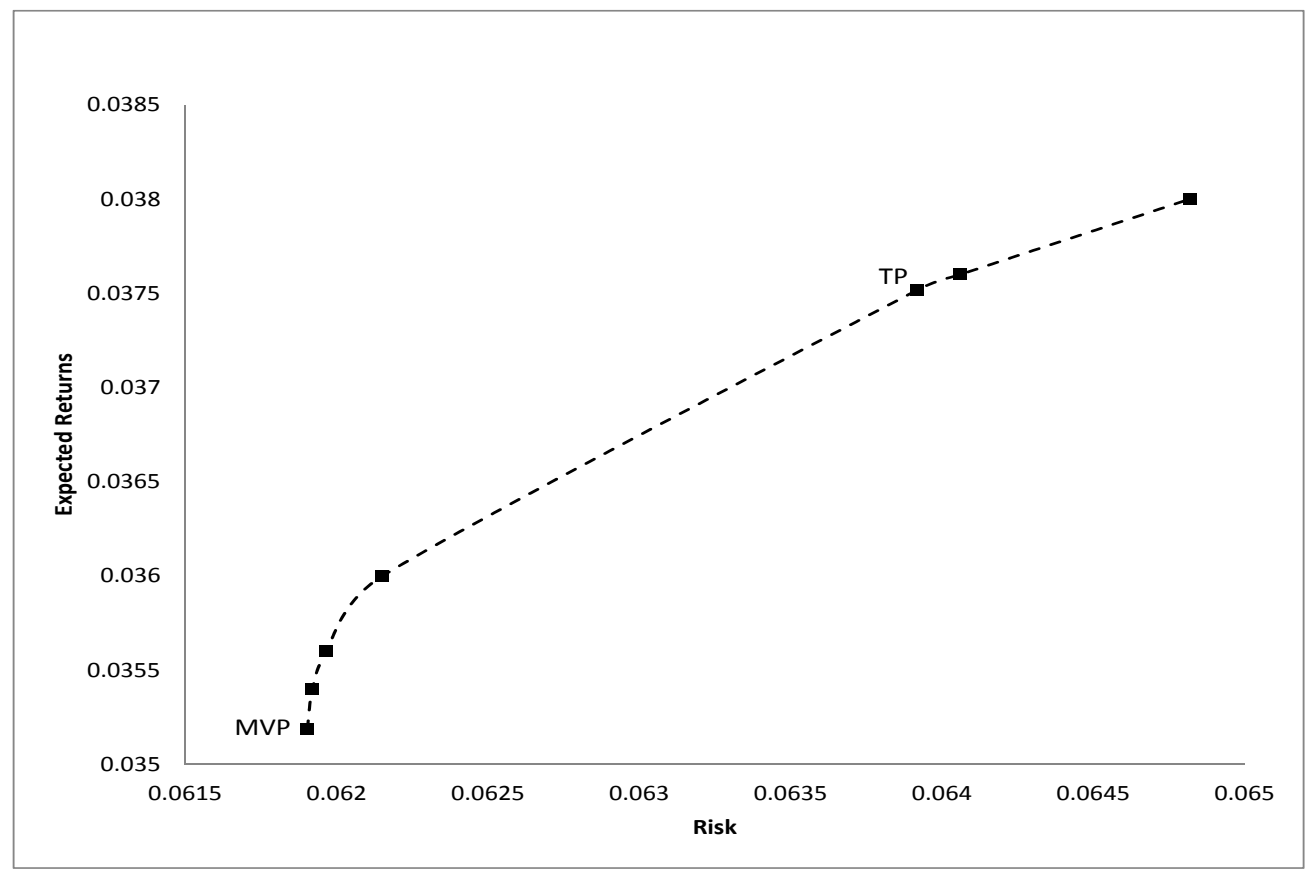

Figure 3. Efficiency frontier 


\section{Conclusions and Recommendation}

In effect, we conclude that on the GSE, individual, a pension fund or a mutual fund has to allocate more than $80 \%$ of wealth to non-financial portfolios for reasonable returns in the period of the study. Majority of the stocks in this portfolio are locally manufacturing firms with no foreign ties. The result is not surprising as the period we considered in our study is characterized by economic instability in the western world. The instability is more likely to affect financial stocks as they show some degree of correlation with their parent firms in the west. We also find that investors, be it individual, mutual fund or pension fund cannot hope to consistently beat the market portfolio (all share indexes). Investor dedicating much time and resources to allocate assets is a waste on the GSE. Investors will earn more profit if they passively hold the market portfolio and forget about active money management altogether. With this, the market knows the best on the GSE.

\section{References}

Fama, Eugene F., \& Kenneth R. French. (2004). The capital asset pricing model: Theory and evidence. Journal of Economic Perspectives, 18, 25-46. http://dx.doi.org/10.1257/0895330042162430

Hung, K., \& C.K. Yang. (2010). A generalized markowtiz portfolio model selection model with higher moments. International Review of Accounting Banking and Finance, 2.

Jarque, Carlos M., \& Anil K. Bera. (1987). A test for normality of observations and regression residuals. International Statistical Review, 55, 163-172. http://dx.doi.org/10.2307/1403192

Jorion, Philippe. (1992). Portfolio optimization in practice. Financial Analysts Journal, 48, 68-74. http://dx.doi.org/10.2469/faj.v48.n1.68

Kon, S. (1984). Models of stock returns, a comparison. Journal of Finance, 39, 147-165.

Markowitz, H. M. (1952). Portfolio selection. Journal of Finance, 7, 77-91.

Markowitz, Harry M., \& Nilufer Usmen. (1996). The likelihood of various stock market return distributions, part 1: Principles of inference. Journal of Risk and Uncertainty, 13, 207-219. http://dx.doi.org/10.1007/BF00056153

Mills, T. C. (1995). Modelling skewness and kurtosis in the london stock exchange ft-se index return distributions. The Statistician, 44, 323-332. http://dx.doi.org/10.2307/2348703

Peiro, A. (1999). Skewness in financial returns. Journal of Banking and Finance, 23, 847-862. http://dx.doi.org/10.1016/S0378-4266(98)00119-8 